\title{
توصيات المؤتهر
}

من أهم التوصيات التي انتهى إليها المؤتمر السنوي الدولي الثالث لقسم القلسفة

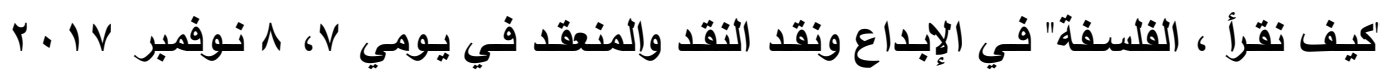

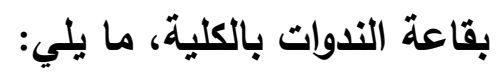
أولاً: ضرورة المحافظة على سلامة اللغة نطقًا وكتابة. ثانيًا: ضيط المصطلحات المستخدمة ضبطًا دقيقًا، لأن المصطلحات هي مفاتيح البحث العلمي.

ثالثًا: التركيز على قراءة النصوص قراءة عصرية، ومحاولية تفسيرها والاستشـهاد بها في معالجة البحث العلمي.

رابعًا: الإهتمام والتركيز على أهمية الخطاب الفلسفيّ وذلك عن طريق السعي لإيجاد

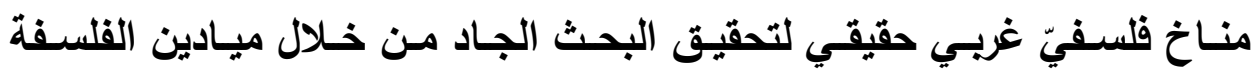

$$
\text { جميعا. }
$$

خامسًا: تحقيق الإستقلال الفكري والمعرفي وذلك بالابتعاد عن تبعية الفكر الغربي. سادسًا: التسيق بين قسم الفلسفة في كلية الآداب/ جامعة الإسكندرية والجمعيات المعنية بالدراسات الفلسفية في مصر والعالم العربي لإنشاء مؤتمر دولي عام في الفلسفة الإدئة يناقش قضايا ومسائل فلسفية في كافة التخصصات.

سابعًا: تخصيص جائزة تمنح لأفضل البحوث لطلبة الماجستير وكذلك الاكتوراه. ثامنًا: التركيز على دراسة أحد اللغات الاجنبية، فراسة اللغة هي لمصب البحث العلمي. 